\title{
КЛ-5
}

\section{ИЗУЧЕНИЕ ГИДРОФИЛЬНЫХ И ГИДРОФОБНЫХ СВОЙСТВ ПОВЕРХНОСТИ ТВЕРДЫХ ТЕЛ МЕТОДОМ ТЕПЛОВИДЕНИЯ}

\author{
Вайнер Б.Г. ${ }^{1,2}$
}

${ }^{1}$ Институт физики полупроводников им. А.В. Ржанова СО РАН, Новосибирск, Россия

${ }^{2}$ Новосибирский национальный исследовательский государственный университет, Новосибирск, Россия

boris-stmt@yandex.ru

DOI: 10.26902/ASFE-11_16

Взаимодействие твердой поверхности с молекулами воды критично для большого числа научных и технических приложений. Гидрофильность во многом определяется адсорбционной связью между водой и твердым телом. При этом на поведение такой гетерогенной системы существенно влияют адсорбированные монослои, расположенные в непосредственной близости от поверхностных атомов. Отсюда, в частности, следует взаимосвязь между свойствами гидрофильности и теплотой адсорбции водяного пара. Последнее делает привлекательным изучение гидрофильных и гидрофобных свойств поверхности с помощью современного тепловизионного метода, способного прецизионно анализировать на количественном уровне тепловые эффекты, возникающие при протекании сорбционных процессов [1-3].

Важное преимущество тепловидения нового поколения перед традиционными способами исследования гидрофильных (гидрофобных) свойств материалов (измерение краевого угла и др.) состоит в том, что данным методом можно изучать начальные стадии взаимодействия молекул воды с поверхностью [2], в том числе, быструю кинетику таких процессов (матричные тепловизоры способны работать с частотой кадров порядка $10^{2} \div 10^{3}$ Гц). Широкое поле обзора камеры позволяет бесконтактным способом реализовать синхронный анализ целой группы (библиотеки) разнотипных образцов в одинаковых экспериментальных условиях (рис. 1), что существенно ускоряет сравнительные исследования и увеличивает достоверность результатов.

Способность современного тепловидения за доли секунды отражать в количественной форме особенности сорбционных явлений делает этот метод чрезвычайно полезным и уникальным при решении многих задач химической физики [3]. К примеру, ИК термографию можно успешно применить для изучения динамики гидрофобизации или, напротив, гидрофилизации поверхностей при адсорбции (хемосорбции) молекул веществ, ориентированных углеводородными цепями в окружающую среду или к твердому телу, соответственно.

В обзорном докладе приведены оригинальные результаты применения матричного тепловидения в задачах, связанных с изучением гидрофильных и гидрофобных свойств поверхности твердых тел разной природы, структуры и химического состава. Прецизионные сорбционные исследования, выполненные в автоматическом режиме, были реализованы с использованием специально созданного для этой цели уникального реактора.
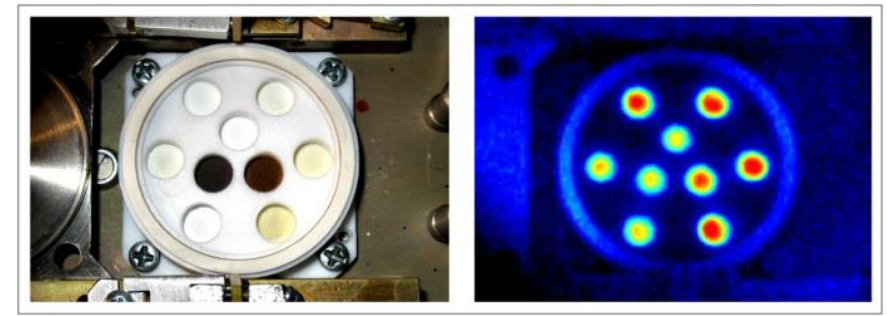

Рис.1. Установленная в реактор библиотека образцов (слева), собранная из 9 разнотипных высокодисперсных твердотельных структур, и ее термограмма (справа), измеренная на одном из этапов эксперимента.

1. B.G. Vainer, In: Measurement 2019, Proc. 12th Int. Conf., May 27-29, 2019, Smolenice, Slovakia. Bratislava: Institute of Measurement Science Slovak Academy of Sciences, p. 150-153 (2019).

2. B.G. Vainer, J. Phys. D: Appl. Phys., 41, p. 065102 (2008).

3. B.G. Vainer, ChemPlusChem, 85, p. 1438-1454 (2020). 